\title{
High admission glucose levels predict worse short-term clinical outcome in non- diabetic patients with acute myocardial infraction: a retrospective observational study
}

\author{
Xiao Song Ding ${ }^{1}$, Shan Shan Wu' ${ }^{2}$, Hui Chen ${ }^{1}$, Xue Qiao Zhao ${ }^{3}$ and Hong Wei Li ${ }^{1,4,5^{*}}$ (D)
}

\begin{abstract}
Background: Patients with acute myocardial infarction (AMI) often accompanied by admission hyperglycemia, which usually predicts a poor clinical outcomes for non-diabetes mellitus. Appropriate cut-point to identify high risk individuals in these patients remains controversial.

Methods: One thousand six hundred ninety-eight non-diabetes AMl patients in this retrospective study were divided into 3 groups according to admission glucose levels (euglycemia group $\leq 140 \mathrm{mg} / \mathrm{dL}$, moderate hyperglycemia group $141-179 \mathrm{mg} / \mathrm{dL}$, severe hyperglycemia group $\geq 180 \mathrm{mg} / \mathrm{dL}$ ). The primary endpoint of this study was all-cause in-hospital mortality rate. In-hospital motality related risk factors was analyzed by multivariate binary logistic regression analyses.

Results: All myocardial necrosis markers and Log NT-proBNP in severe hyperglycemia group were significantly higher than those in the other 2 groups. Logistic regression showed that independent predictors of the in-hospital mortality rate in non-diabetic patients with $\mathrm{AMl}$ were age $(\mathrm{OR}=1.057,95 \% \mathrm{Cl} 1.024-1.091, P<0.001)$, logarithm of the $\mathrm{N}$-terminal pro-brain natriuretic peptide $(\mathrm{OR}=7.697,95 \% \mathrm{Cl} 3.810-15.550, P<0.001)$, insufficient myocardial reperfusion $(\mathrm{OR}=7.654,95 \% \mathrm{Cl} 2.109-27.779, P<0.001)$, percutaneous coronary intervention $(\mathrm{OR}=0.221,95 \% \mathrm{Cl} 0.108-0.452$, $P<0.001)$ and admission glucose (as categorical variable). Patients with moderate hyperglycemia $(\mathrm{OR}=1.186,95 \% \mathrm{Cl}$ $0.585-2.408, P=.636)$ and severe hyperglycemia $(\mathrm{OR}=4.595,95 \% \mathrm{Cl} 1.942-10.873, P=0.001)$ had a higher all-cause inhospital mortality rate compared with those with euglycemia after AMl in non-diabetic patients.

Conclusions: The all-cause in-hospital mortality risk increases remarkably as admission glucose levels elevated in nondiabetic patients with AMl, especially in patients with admission glucose levels $\geq 180 \mathrm{mg} / \mathrm{dL}$. Severe admission hyperglycemia could be regarded as prospective high-risk marker for non-diabetic AMI patients.
\end{abstract}

Keywords: Acute myocardial infarction, Admission hyperglycemia, Non-diabetes mellitus, In-hospital mortality

\footnotetext{
* Correspondence: Ihw19656@sina.com

'Department of Cardiology, Cardiovascular Center, Beijing Friendship Hospital, Capital Medical University, 95 Yong An Road, Xi Cheng District, Beijing 100050, People's Republic of China

${ }^{4}$ Department of Internal Medicine, Medical Health Center, Beijing Friendship

Hospital, Capital Medical University, 95 Yong An Road, Xi Cheng District,

Beijing 100050, People's Republic of China

Full list of author information is available at the end of the article
}

(c) The Author(s). 2019 Open Access This article is distributed under the terms of the Creative Commons Attribution 4.0 International License (http://creativecommons.org/licenses/by/4.0/), which permits unrestricted use, distribution, and reproduction in any medium, provided you give appropriate credit to the original author(s) and the source, provide a link to the Creative Commons license, and indicate if changes were made. The Creative Commons Public Domain Dedication waiver (http://creativecommons.org/publicdomain/zero/1.0/) applies to the data made available in this article, unless otherwise stated. 


\section{Background}

Many studies have shown that admission hyperglycemia (AHG) is common in patients with acute coronary syndrome (AMI) [1] and is also a risk factor for in-hospital death and complications [2]. Previous epidemiological studies have shown that approximately 25 to $50 \%$ of patients with AMI have co-existing hyperglycemia [3]. Recent studies have suggested that the effect of hyperglycemia on the outcomes of patients with AMI differs between patients with diabetes and those with previously undiagnosed diabetes [4]. The risks of cardiovascular events are higher in patients with acute myocardial infarction (AMI) who have not been diagnosed with diabetes mellitus (DM) or whose DM is diagnosed only after admission than in patients with AMI and normal blood glucose levels. Therefore, hyperglycemia is more predictive of adverse events in non-diabetic patients with AMI than in in those with DM [5]. Previous studies have analyzed the effect of insulin treatment for controlling admission blood glucose levels for a reduction in recent adverse events in patients with AMI [6]. However, there is no clear conclusion on which level of blood glucose control can benefit non-diabetic patients. In this retrospective study, we compared baseline data and the incidence of adverse events during hospitalization in nondiabetic patients with AMI with different admission blood glucose levels to determine possible influential factors.

\section{Methods}

\section{Study population}

This retrospective study was based on data from the Cardiovascular Center of Beijing Friendship Hospital Data Bank (CBD BANK). The study protocol was approved by the Beijing Friendship Hospital ethics committee (certification number: 2018-P2-051-01). A total of 3527 patients who were diagnosed with AMI (including ST-segment elevation myocardial infarction [STEMI] and non-STsegment elevation myocardial infarction [NSTEMI]) during hospitalization in our hospital from January 2013 to March 2018 were identified by a search strategy. A total of 219 patients without blood glucose data at admission and 304 repeat hospital patients and 1306 patients with DM were excluded. Finally, 1698 patients were included in the final analysis. The optimal medical therapy for AMI was administered in every patient during hospitalization, according to the current guidelines. They were treated with dura antiplatelet drugs (aspirin plus clopidogrel/ticagrelor), ACEI, $\beta$ blocker, statin were used as secondary prevention unless there were contraindications. Coronary angiography and percutaneous coronary intervention were performed if the doctors believe patients could benefit from the opration. These patients were divided into 3 groups according to the admission glucose (the first blood test analysis on admission) level as follows: euglycemia group, admission glucose levels $\leq 140 \mathrm{mg} / \mathrm{dL}$ (group $1, n=$ 1216); moderate hyperglycemia group, admission glucose levels > 140 and < $180 \mathrm{mg} / \mathrm{dL}$ (group 2, $n=370$ ); and severe hyperglycemia group, admission glucose levels $\geq 180$ $\mathrm{mg} / \mathrm{dL}$ (group 3, $n=112$ ). A flow chart of the cohort is shown in Fig. 1.

\section{Data collection and definitions}

All individuals had a 12-lead electrocardiogram, transthoracic echocardiography, and laboratory tests (complete blood count, electrolytes, creatinine, lipid profile, glucose, and markers of myocardial necrosis) performed. The results of coronary angiography, percutaneous coronary intervention $(\mathrm{PCI})$, and qualification for further treatment (conservative or invasive), as well as clinical event data during hospitalization, were collected. All of the eligible patients who were enrolled met the Third Universal Definition of Myocardial Infarction for AMI [7] as follows: detection of a rise and/fall on cardiac biomarker values (preferably cardiac troponin $\left[\mathrm{cTn}^{\prime}\right]$ ) with at least one value above the 99th percentile upper reference limit and with at least one of the following factors. These factors were symptoms of ischemia, new or presumed new significant ST-segment-T wave changes or new left bundle branch block, development of pathological Q waves in an electrocardiogram, and imaging evidence of new loss of viable myocardium or new regional wall motion abnormality. Patients with DM were excluded on the basis of American Diabetes Association criteria as follows [8]: a history of diabetes; or the diagnosis of DM was made during hospitalization on the basis of an oral glucose tolerance test, fasting plasma glucose levels $\geq 126 \mathrm{mg}$ / $\mathrm{dL}$, 2-h plasma glucose levels $\geq 200 \mathrm{mg} / \mathrm{dL}$, or glycosylated hemoglobin $(\mathrm{HbA} 1 \mathrm{c}) \geq 6.5 \%$.

\section{Study endpoints}

The primary endpoint of this study was the all-cause inhospital mortality rate. In-hospital mortality was defined as death caused by all causes, including cardiac and non-cardiac death. Complications during hospitalization were defined as cardiogenic shock, stroke (including cerebral infarction and cerebral hemorrhage), fatal rapid arrhythmia (including ventricular tachycardia and ventricular fibrillation), and atrioventricular block (including second- and third-grade atrioventricular block) during hospitalization. The MACEs (major adverse cardiovascular events) were considered as secondary composite endpoint including: cardiovascular mortality, cardiogenic shock, ischemic stroke, fatal rapid arrhythmia and atrioventricular block.

\section{Statistical analysis}

To avoid decreased statistical power and bias caused by the direct rule-out of missing data, we used multiple 


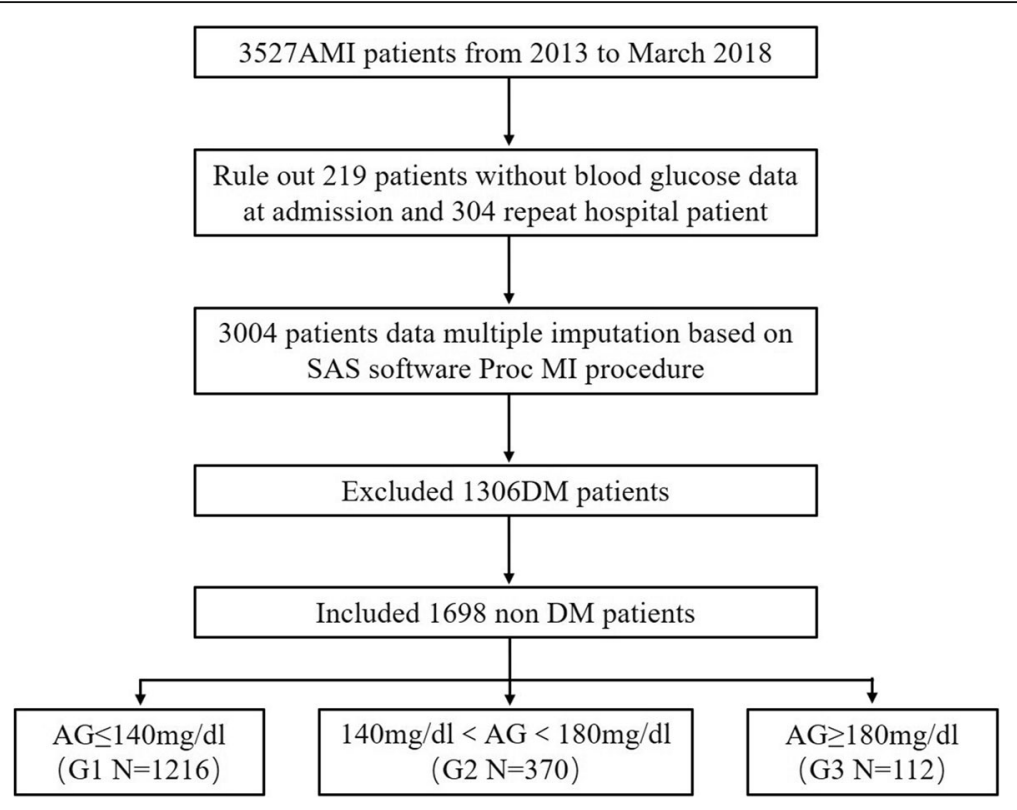

Fig. 1 Patients screening flow chart. Acute myocardium infarction (AMI), Diabetes mellitus (DM), Admission glucose (AG)

imputations before excluding patients with DM using the SAS software version 9.0 Proc MI procedure (SAS Institute, Cary, NC, USA) to account for missing data. The data were analyzed by SPSS software, version 20.0 (SPSS, Chicago, IL). Continuous variables are expressed as the median (P25, P75) and were compared by using the non-parametric rank sum test. Because none of these variables were normally distributed. Because $\mathrm{N}$-terminal pro-brain natriuretic peptide (NT-proBNP) was extremely skewed distribution, it was log-transformed into a new variable $\log$ NT-proBNP. Categorical data are expressed by rates and proportions, and were analyzed by chi-square analysis. The relationship between admission glucose categories with in-hospital motality and other events was analyzed by using multivariate binary logistic regression analyses. First, univariate analysis of the following variables was performed: age, gender, age older than 75 years, left ventricular ejection fraction < 0.4, STEMI, percutaneous coronary intervention, insufficient myocardial reperfusion (postoperative blood flow< Thrombolysis in Myocardial Infarction TIMI 3), history of myocardial infarction, hypertension, hyperlipidemia, history of chronic kidney disease, history of cerebrovascular disease, current smoking, systolic blood pressure at admission, fasting plasma glucose levels on the day after admission, admission glucose levels, HbA1c, highsensitivity C-reactive protein levels, total cholesterol levels, low-density lipoprotein cholesterol levels, creatinine levels, estimated glomerular filtration rate (eGFR), peak creatine kinase-MB (CK-MB) value, peak cardiac troponin I value, peak myoglobin (MYO) value, and left ventricular ejection fraction. Five variables including age, log NT-proBNP, PCI, Insufficient myocardium reperfusion and admission glucose were included in the final regression model. Variables with a $P$ value $<0.05$ were then included in the logistic regression equation to analyze the risk factors associated with all-cause inhospital mortality. All analyses were 2-tailed and a $P$ value $<0.05$ was considered statistically significant. Adjusted $P$ values $(\alpha=0.05 / 3=0.016)$ were used in the pairwise comparison of in-hospital motality and other adverse events (Cardiac Motality, Cardiac Shock, Tachycardia, AVB) among the three groups.

\section{Results}

Baseline data of continuous and categorical variables among the groups after being categorized by admission blood glucose levels are shown in Table 1. The severe hyperglycemia group had higher fasting blood glucose $(P<0.001)$ and HbA1c values $(P<0.001)$. The mean admission glucose value of the 12 patients died in group 3 was $228.76 \mathrm{mg} / \mathrm{dl}$, maximum value $311.58 \mathrm{mg} / \mathrm{dl}$, minimal value $182.34 \mathrm{mg} / \mathrm{dl}$ and SD $41.64 \mathrm{mg} / \mathrm{dl}$ (data not show in Table 1). All myocardial necrosis markers and Log NTproBNP in severe hyperglycemia group were significantly higher than those in the other 2 groups. CK-MB $(P<$ $0.001)$, cardiac troponin $\mathrm{I}(P<0.001), \mathrm{MYO}(P<0.001) \log$ NT-proBNP was also significantly higher in severe hyperglycemia group than in the other 2 groups, which corresponded to a lower ejection fraction. For admission medications, there were no significant difference between three groups (Table 1).

The in-hospital all-cause mortality rate and cardiac mortality rate significantly elevated as admission blood glucose 
Table 1 Baseline characteristics of non-DM patients stratified according to admission glucose

\begin{tabular}{|c|c|c|c|c|}
\hline & $\begin{array}{l}\mathrm{AG} \leq 140 \mathrm{mg} / \mathrm{dL} \\
\mathrm{M}(\mathrm{P} 25, \mathrm{P} 75) \\
N=1216\end{array}$ & $\begin{array}{l}140 \mathrm{mg} / \mathrm{dL}<\mathrm{AG}<180 \mathrm{mg} / \mathrm{dL} \\
\mathrm{M}(\mathrm{P} 25, \mathrm{P} 75) \\
N=370\end{array}$ & $\begin{array}{l}A G \geq 180 \mathrm{mg} / \mathrm{dL} \\
M(P 25, P 75) \\
N=112\end{array}$ & $P$ \\
\hline Age (years) & $63(55,76)$ & $64(57,76)$ & $66(57,73)$ & 0.022 \\
\hline SBP $(\mathrm{mmHg})$ & $127(114,141)$ & $124.00(109.75,138.00)$ & $125.5(110.00,143.75)$ & 0.008 \\
\hline FPG (mg/dL) & $91.08(83.16,101.11)$ & $101.7(91.26,114.71)$ & $109.17(92.88,136.80)$ & $<0.001$ \\
\hline $\mathrm{AG}(\mathrm{mg} / \mathrm{dL})$ & $114.12(103.36,125.77)$ & $153.36(146.11,163.8)$ & $204.75(190.21,229.63)$ & $<0.001$ \\
\hline $\mathrm{HbA} 1 \mathrm{C}(\%)$ & $5.60(5.3,5.8)$ & $5.70(5.4,6.0)$ & $5.80(5.60,6.20)$ & $<0.001$ \\
\hline hs-CRP (ng/ml) & $6.77(2.25,15.26)$ & $7.47(2.58,15.95)$ & $8.93(2.64,21.21)$ & 0.201 \\
\hline TC $(\mathrm{mmol} / \mathrm{L})$ & $4.34(3.72,5.08)$ & $4.39(3.75,4.99)$ & $4.23(3.58,4.81)$ & 0.363 \\
\hline LDL-C (mmol/L) & $2.51(2.02,3.04)$ & $2.50(2.06,2.97)$ & $2.44(1.93,2.87)$ & 0.250 \\
\hline $\mathrm{Cr}(\mathrm{mg} / \mathrm{dL})$ & $0.95(0.84,1.09)$ & $1.05(0.83,1.08)$ & $0.98(0.84,1.20)$ & 0.228 \\
\hline eGFR (ml/min.1.73m²) & $80.70(64.52,94.89)$ & $77.26(65.51,93.53)$ & $76.51(60.17,87.93)$ & 0.094 \\
\hline log NT-proBNP & $3.16(2.68,3.66)$ & $3.27(2.78,3.80)$ & $3.33(2.99,3.87)$ & $<0.001$ \\
\hline CK-MB ( ng/ml) & $32.10(4.5,105.16)$ & $59.89(7.9,165.75)$ & $74.90(17.35,209.25)$ & $<0.001$ \\
\hline cTnl (ng/ml) & $3.31(0.53,13.23)$ & $6.21(0.56,20.17)$ & $5.95(1.18,33.28)$ & $<0.001$ \\
\hline MYO (ng/ml) & $101.5(35.6,250.94)$ & $150.50(49.83,301.36)$ & $175.39(82.78,428.25)$ & $<0.001$ \\
\hline EF & $0.61(0.54,0.66)$ & $0.59(0.51,0.66)$ & $0.58(0.51,0.64)$ & 0.003 \\
\hline HS (day) & $8.0(6.0,10.0)$ & $8.0(6.0,11.0)$ & $8.0(6.0,10.0)$ & 0.149 \\
\hline Male & $930(76.5)$ & $269(72.7)$ & $130(76.8)$ & 0.32 \\
\hline Age over 75 & $324(26.6)$ & $110(29.7)$ & $25(22.3)$ & 0.25 \\
\hline EF below 0.4 & $88(7.2)$ & $27(7.3)$ & $7(6.2)$ & 0.92 \\
\hline STEMI & $585(48.1)$ & $229(61.9)$ & $75(67.0)$ & $<0.001$ \\
\hline $\mathrm{PCl}$ & 883 (72.6) & $285(77.0)$ & $89(79.5)$ & 0.09 \\
\hline IMR & $14(1.2)$ & $15(4.1)$ & $6(5.4)$ & $<0.001$ \\
\hline $\mathrm{OMl}$ & $130(10.7)$ & $43(11.6)$ & $11(9.8)$ & 0.82 \\
\hline Hypertension & $7718(59.0)$ & $241(65.1)$ & $72(64.3)$ & 0.08 \\
\hline Dyslipidemia & $511(42.0)$ & $170(45.9)$ & $52(46.4)$ & 0.32 \\
\hline CKD & $55(4.5)$ & $19(5.1)$ & $5(4.5)$ & 0.88 \\
\hline Stroke history & $167(13.7)$ & 65 (17.6) & $14(12.5)$ & 0.15 \\
\hline Current smoking & $589(48.4)$ & $159(43.0)$ & $48(42.9)$ & 0.12 \\
\hline \multicolumn{5}{|c|}{ Medication befor admission } \\
\hline Aspirin & $134(11)$ & $33(8.9)$ & $16(14.3)$ & 0.24 \\
\hline CCB & $325(26.7)$ & $115(31.1)$ & $37(33.0)$ & 0.13 \\
\hline$\beta$-blocker & $131(10.8)$ & $48(13.0)$ & $13(11.6)$ & 0.50 \\
\hline ACEI & $104(8.6)$ & $36(9.7)$ & $9(8.0)$ & 0.75 \\
\hline ARB & $177(14.6)$ & $44(11.9)$ & $19(17)$ & 0.29 \\
\hline Statin & $136(11.2)$ & $56(15)$ & $10(8.9)$ & 0.07 \\
\hline
\end{tabular}

AG Admission glucose, SBP Systolic blood pressure, FPG Fasting plasma glucose, HbA1c Glycosylated hemoglobin, $h s$-CRP High-sensitivity C-reactive protein, TC Total cholesterol, LDL-C Low-density lipoprotein cholesterol, $\mathrm{Cr}$ Creatinine, eGFR estimated glomerular filtration rate, NT-proBNP N-terminal pro-brain natriuretic peptide, CK-MB Creatine kinase-MB, CTnI Cardiac troponin I, MYO Myoglobin, EF Ejection fraction, HS Hospital stay, STEMI ST-segment elevation myocardial infraction, $P C I$ Percutaneous coronary intervention, IMR Insufficient myocardium reperfusion, $O M I$ Old myocardial infraction, CKD Chronic Kidney Disease, CCB Calcium channel blocker, ACEI Angiotensin-converting enzyme inhibitor, ARB Angiotensin receptor blocker

levels increased. Other adverse events rates gradually increased with admission blood glucose categories grade up and differences of total MACE events between any 2 of the 3 groups were statistically significant. There were significant differences in all-cause and cardiac motality between groups 2 and 3, not between group 1 and 2 (Figs. 2, 3 and 4).

Logistic regression analysis showed that admission glucose was one of the independent predictors of the inhospital mortality. The in-hospital all-cause motality risk 


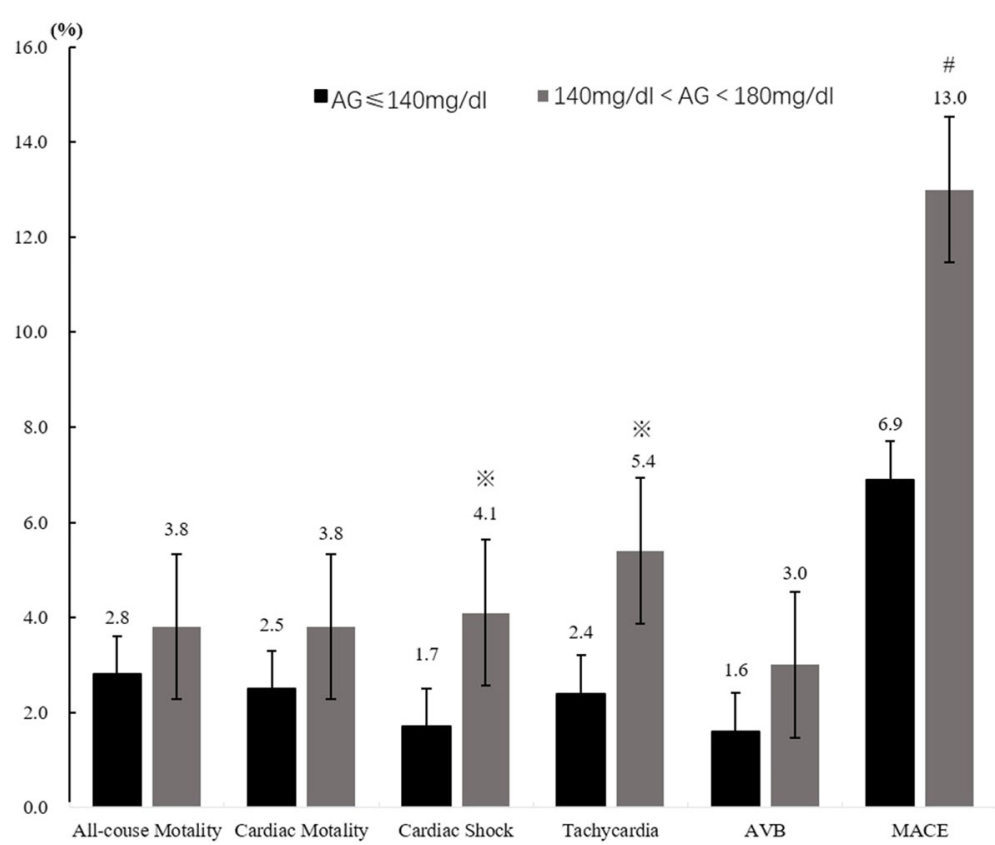

Fig. 2 All-cause mortality and complications comparison between euglycemia group and moderate hyperglycemia groups. $※ P<0.01$, \#P<0.001, AVB Atrioventricular block, MACE Major adverse cardiovascular events

comparisons between groups 3 and 1 and groups 3 and 2 were statistical significant $(\mathrm{OR}=4.595, \mathrm{P}<0.001$ and 3.873, $P=0.006$ respectively, Table 2 ).

\section{Discussion}

In the current study, we analyzed in-hospital mortality rate and other comorbidities of AMI patients without DM grouped by two admission blood glucose cut-point value $(140 \mathrm{mg} / \mathrm{dL}$ and $180 \mathrm{mg} / \mathrm{dL})$. We found that, patients with moderate hyperglycemia and severe hyperglycemia had higher in-hospital mortality rates after AMI compared with patients with euglycemia patients. MACE events rise up parallelly with admission glucose upgrade. Logistic regression analysis showed that admission glucose was a independent predictors of the in-hospital mortality rate in non-diabetic AMI patients. In-hospital motality risk of the severe hyperglycemia was 3.873 folds $(P=0.006)$ than moderate admission hyperglycemia group.

Several decades ago, AHG was recognized as a common phenomenon in patients with AMI. The incidence of AHG ranges from 51 to $61.7 \%$ (with a cut-off value of $140 \mathrm{mg} / \mathrm{dL}$ ) [3]. Increased blood glucose levels in patients with AMI have been described as AHG, high admission blood glucose levels, acute hyperglycemia, and stress hyperglycemia [9]. The American Heart Association Diabetes Committee defined AMI accompanied by stress hyperglycemia as an admission plasma glucose level of $>140 \mathrm{mg} / \mathrm{dL}$ in its scientific statement [10]. However, AHG cut-off values differ in different studies. The American Diabetes Association recommends that patients with severe disease have blood glucose levels > $180 \mathrm{mg} / \mathrm{dL}$ and need to start insulin treatment, and the recommended target glucose range is from 140 to 180 $\mathrm{mg} / \mathrm{dL}$ [11]. Therefore, in this study, we set the grouping cut-points as $140 \mathrm{mg} / \mathrm{dL}$ and $180 \mathrm{mg} / \mathrm{dL}$.

Some clinicians consider that AHG is only a criterion reflecting severity of AMI because it is common in patients who are older, diabetic, and have STEMI with acute heart failure [12]. However, the definite relationship between AHG and short and long-term poor prognoses shows that AHG is also a factor that contributes to progression of disease [2].

AHG often predicts a poor short- or long-term prognosis in patients with AMI. The in-hospital mortality rate was 3.6 times higher and the 1- to 3-year mortality rate was 2.26 times higher in patients with AMI and AHG than in those without AHG [5] There are several explanations for hyperglycemia in patients with AMI. Previous studies have shown that catecholamine and steroid hormone levels are significantly increased and positively correlated with stress levels in patients with AMI [13, 14]. Additionally, a stress-induced elevation in catecholamine levels can inhibit pancreatic $\beta$-cell function and thus cause a decline in insulin levels [15]. Whether this hyperglycemic response is associated with more myocardial infarction events, with impaired myocardial function, or both remains unclear.

In a previous study, in patients with AHG, the proportion of low TIMI flow scores was higher than that in patients with normal blood glucose levels after PCI [16]. 


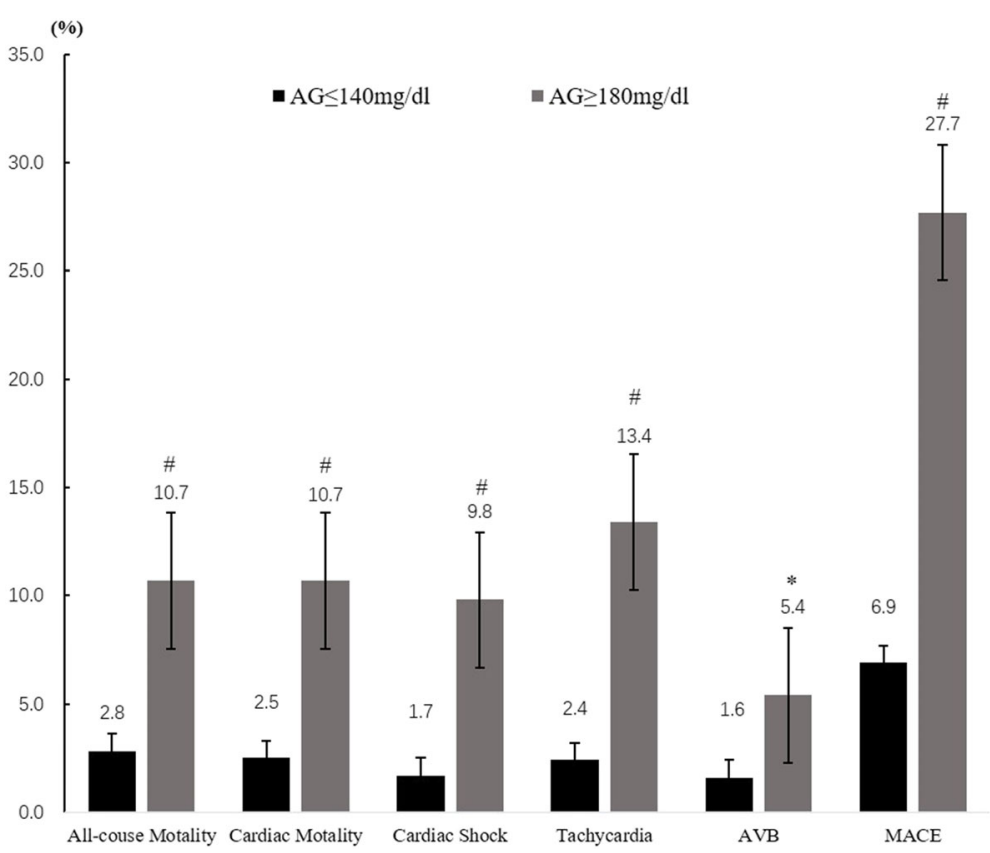

Fig. 3 All-cause mortality and complications comparison between euglycemia group and severe hyperglycemia. ${ }^{*} P<0.05, \# P<0.001$, AVB Atrioventricular block, MACE Major adverse cardiovascular events

Infarct size was larger [17], and the incidence rates of malignant arrhythmia [18] and cardiac shock [19] were also higher in patients with AHG, especially in non-DM patients than in those without AHG [16]. In the current study, CK-MB, cardiac troponin I, and MYO levels were higher in the severe hyperglycemia group of non-DM patients with AMI. This finding suggested that myocardial injury was in parallel with admission blood glucose levels. This result is accordance with previous study [3]. There are several possible mechanisms to explain the association between AHG and AMI adverse events. Hyperglycemia leads to thrombogenesis by activating platelets

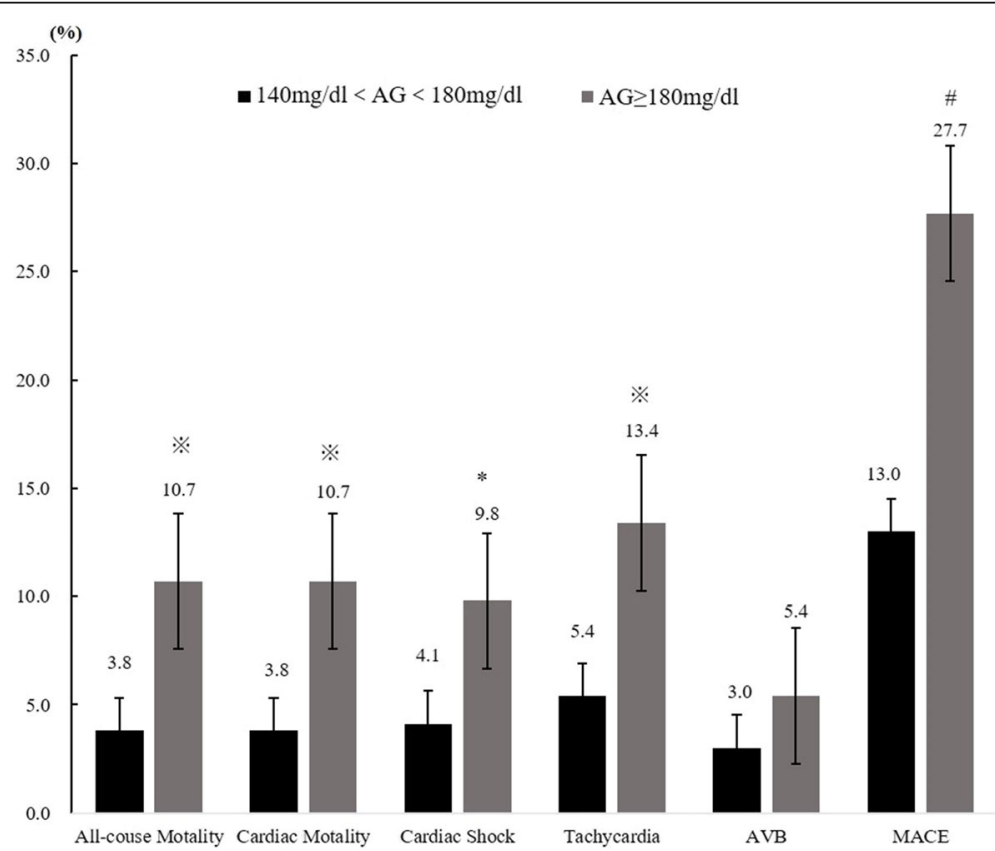

Fig. 4 All-cause mortality and complications comparison between moderate hyperglycemia group and severe hyperglycemia. ${ }^{*} p<0.05$, $※ P<0.01$, $\# P<0.001$, AVB Atrioventricular block, MACE Major adverse cardiovascular events 
Table 2 Binary logistic regression analysis of in-hospital allcause mortality-related factors

\begin{tabular}{lllll}
\hline & OR & $95 \%$ C.I. & & $P$ \\
\hline Age & 1.057 & 1.024 & 1.091 & 0.001 \\
Log NT-proBNP & 7.697 & 3.810 & 15.550 & $<0.001$ \\
PCI & .221 & .108 & .452 & $<0.001$ \\
IMR & 7.654 & 2.109 & 27.779 & 0.002 \\
AG (VS Group1) & & & & \\
$\quad$ Group2 & 1.186 & .585 & 2.408 & 0.636 \\
$\quad$ group3 & 4.595 & 1.942 & 10.873 & 0.001 \\
AG (VS Group2) & & & & \\
$\quad$ Group3 & 3.873 & 1.485 & 10.100 & 0.006 \\
\hline
\end{tabular}

OR Odds ratio, C.I. Confidence interval, Log NT-proBNP Logarithm of the Nterminal pro-brain natriuretic peptide, $P C l$ Percutaneous coronary intervention, IMR Insufficient Myocardium Reperfusion, AG Admission glucose, Group 1 admission blood glucose $\leq 140 \mathrm{mg} / \mathrm{dL}$, group 2 admission blood glucose $>140$ and $<180 \mathrm{mg} / \mathrm{dL}$, group 3 admission blood glucose $\geq 180 \mathrm{mg} / \mathrm{dL}$

and affects fibrinolysis [20, 21]. Hyperglycemia is associated with the no-reflow phenomenon [22]. Furthermore, other factors, including oxidative stress [23], insulin resistance, and massive catecholamine production increase free fatty acid levels, and excessively high free fatty acid levels have toxic effects on infarcted and ischemic myocardium [15]. Another potential mechanism may include endothelium disfunction that occurs in patients with admission hyperglycemia [24].

Many studies have reported that AMI accompanied by AHG is an independent predictor of heart failure and death [19]. These clinical outcomes are even worse in non-diabetes patients [5]. A study on the relationship between AHG and left ventricular function showed that patients with acute AHG before revascularization had a lower postoperative left ventricular ejection fraction than did those without AHG [3]. Furthermore, those patients had a significantly lower left ventricular ejection fraction before discharge and significantly less improvement in left ventricular function. This study suggested that acute AHG can impair left ventricular function, even after successful revascularization. In our study, we found that patients with high admission blood glucose levels were more likely to have poor coronary artery flow and a lower ejection fraction after PCI, which is consistent with previous studies [25].

Most previous studies on the clinical outcomes of patients with AHG and AMI were conducted in Western countries, but a few studies examined these outcomes in Asian populations. Several Chinese studies have investigated the relationships between blood glucose levels at admission and clinical outcomes. In a preliminary study in our center, Song et al. concluded that AHG should be regarded as a strong risk factor for in-hospital and 2year all-cause mortality in patients with AMI [26]. Li et al. also found that the in-hospital mortality rate began to rise in patients with non-DM and blood glucose levels of $162 \mathrm{mg} / \mathrm{dl}$ or higher [27]. Another study that focused on the prognosis of Chinese patients with non-DM and AMI showed that the 7- and 30-day mortality rates gradually increased with increasing blood glucose levels at admission, and elevated HbAlc levels showed that AHG was an independent predictor of in-hospital mortality, but elevated HbA1c levels were not [28]. Logistic regression analysis in our study also showed that admission blood glucose levels $\geq 180 \mathrm{mg} / \mathrm{dL}$ were an independent predictive factor associated with in-hospital mortality, except for the variates of age, log NT-proBNP, PCI treatment, and insufficient myocardial reperfusion.

Patients with AMI and undiagnosed diabetes, even if their blood glucose levels are elevated on admission, do not receive sufficient attention and adequate medical treatment in most cases. Early positive glycemic therapy is thought to improve the clinical outcome, but several clinical studies have shown that mortality rates do not improve [29]. This finding may be related to failure of controlling blood glucose levels according to the protocol or a stratified analysis strategy was not used for diabetic and non-diabetic patients [30]. Our study suggests that blood glucose control of non-diabetic patients with $180 \mathrm{mg} / \mathrm{dL}$ as the target of control may help to reduce the in-hospital mortality risk and adverse events. However, more prospective therapeutic clinical studies are required to confirm this conclusion.

\section{Study limitations}

There are several limitations of this study. It's a singlecenter observational study based on retrospective design, and the course of hyperglycemia was not all evaluated after the acute event, even some patients rechecked by OGTT test, that means some patients could have had undiagnosed DM or impaired glucose tolerance on admission and may have been included in our study group. The in-hospital management of hyperglycemia and used glycemic target choice were not included. Long-term patient follow-up should carried out, that would be helpful to define long term effects.

\section{Conclusion}

Our study shows that the all-cause in-hospital mortality risk remarkably increases in non-diabetic patients with AMI and elevated blood glucose levels at admission, especially in patients with admission glucose levels $\geq 180$ $\mathrm{mg} / \mathrm{dL}$. Severe admission glucose elevation could be a useful marker for identifying patients with a high mortality risk in non-diabetic AMI patients.

\section{Abbreviations}

AHG: Admission hyperglycemia; AMl: Acute myocardial infarction; AVB: Atrial ventricular block; CK-MB: Creatine kinase-MB; CTn: Cardiac troponin; DM: Diabetes mellitus; eGFR: Estimated glomerular filtration rate; 
HbA1c: Glycosylated hemoglobin; Log NT-proBNP: Logarithm of the Nterminal pro-brain natriuretic peptide; MACEs: Major adverse cardiovascular events; MYO: Myoglobin; NSTEMI: Non-ST-segment elevation myocardial infarction; PCI: Percutaneous coronary intervention; STEMI: ST-segment elevation myocardial infarction; TIMI: Thrombolysis in myocardial infarction

\section{Acknowledgments}

We sincerely thank all of the people working for the Data Bank of the Cardiovascular Center of Beijing Friendship Hospital, especially Zhao Guo Liang (data manager), Zhu Jie, Li Ao, and other members who contributed to gathering data and data entry. We also thank Dr. Shi Yu, PhD for assistance in statistical analysis.

\section{Authors' contributions}

XSD, XQZ, and HWL designed the research; XSD analyzed and interpreted the data; XSD, SSW performed the statistical analysis; XSD wrote the manuscript; $\mathrm{HC}$ and HWL critically revised the manuscript for key intellectual content; All authors approved the final version of the manuscript. HWL is responsible for the integrity of the work as a whole.

\section{Funding}

This study was supported by the National Natural Science Foundation of China (No. 81670315).

\section{Availability of data and materials}

The datasets used and analysed during the present study are available from the corresponding author on reasonable request.

\section{Ethics approval and consent to participate}

Ethical approval was obtained from Beijing Friendship Hospital ethics committee (certification number: 2018-P2-051-01). This retrospective study was conducted without informed consent for some objective reasons and was approved by the ethics committee. All study procedures were performed in accordance with Declaration of Helsinki.

\section{Consent for publication}

Not applicable.

\section{Competing interests}

The authors declare that they have no competing interests.

\section{Author details}

'Department of Cardiology, Cardiovascular Center, Beijing Friendship Hospital, Capital Medical University, 95 Yong An Road, Xi Cheng District, Beijing 100050, People's Republic of China. ${ }^{2}$ National Clinical Research Center of Digestive Diseases, Beijing Friendship Hospital, Capital Medical University, 95 Yong An Road, Xi Cheng District, Beijing 100050, People's Republic of China. ${ }^{3}$ Clinical Atherosclerosis Research Lab, Division of Cardiology, University of Washington, 1959 NE Pacific Street, Seattle, WA, USA. ${ }^{4}$ Department of Internal Medicine, Medical Health Center, Beijing Friendship Hospital, Capital Medical University, 95 Yong An Road, Xi Cheng District, Beijing 100050, People's Republic of China. ${ }^{5}$ Beijing Key Laboratory of Metabolic Disorder Related Cardiovascular Disease, Beijing 100069, People's Republic of China.

Received: 13 March 2019 Accepted: 24 June 2019 Published online: 04 July 2019

\section{References}

1. Arnold SV, Lipska KJ, Li Y, Mcguire DK, Goyal A. Prevalence of glucose abnormalities among patients presenting with an acute myocardial infarction. Am Heart J. 2014;168(4):466-70.

2. Singh K, Hibbert B, Singh B, Carson K, Premaratne M, Le May M, et al. Metaanalysis of admission hyperglycaemia in acute myocardial infarction patients treated with primary angioplasty: a cause or a marker of mortality? Eur Heart J Cardiovasc Pharmacother. 2015;1(4):220-8.

3. Mansour AA, Wanoose HL. Acute phase hyperglycemia among patients hospitalized with acute coronary syndrome: prevalence and prognostic significance. Am J Cardiol. 2014;114(12):1789-93.
4. Kim EJ, Jeong MH, Kim JH, Ahn TH, Seung KB. Clinical impact of admission hyperglycemia on in-hospital mortality in acute myocardial infarction patients. Int J Cardiol. 2017;236:9-15.

5. Pararajasingam G, Høfsten DE, Løgstrup BB, Egstrup M. Newly detected abnormal glucose regulation and long-term prognosis after acute myocardial infarction: comparison of an oral glucose tolerance test and glycosylated haemoglobin A1c. Int J Cardiol. 2016;214:310-5.

6. Selker HP, Udelson JE, Massaro JM, Ruthazer R, D'Agostino RB, Griffith JL, et al. One-year outcomes of out-of-Hospital Administration of Intravenous Glucose, insulin, and potassium (GIK) in patients with suspected acute coronary syndromes (from the IMMEDIATE [Immediate myocardial metabolic enhancement during initial assessment and treatment in emergency Care] trial). Am J Cardiol. 2014;113(10):1599-605.

7. Thygesen K, Alpert JS, Jaffe AS, Simoons ML, Chaitman BR, White HD. Third universal definition of myocardial infarction. Circulation. 2012;126(16):2020-35.

8. Kalyani RRDSBE. American diabetes Association2. Classification and diagnosis of diabetes: standards of medical Care in Diabetes-2018. Diabetes Care. 2017;41(Supplement 1):S13-27.

9. Koracevic GP. Proposal of a new approach to study and categorize stress hyperglycemia in acute myocardial infarction. J Emerg Med. 2016;51(1):31-6.

10. Deedwania P, Kosiborod M, Barrett E, Ceriello A, Isley W, Mazzone T, et al. Hyperglycemia and acute coronary syndrome: a scientific statement from the American Heart Association diabetes Committee of the Council on nutrition, physical activity, and metabolism. CIRCULATION. 2008;117(12):1610-9.

11. RW G, NG C, CV D. American diabetes association: standards of medical care in diabetes--2014. Diabetes Care. 2013;37(Supplement_1):S14-80.

12. Dąbek J, Bałys M, Majewski M, Gąsior Z. Diabetic patients with an acute myocardial infarction in terms of risk factors and comorbidities management: characteristics of the highest-risk individuals. Adv Clin Exp Med. 2016;25(4):655-63.

13. Cheung NW, Wong KYC, Kovoor P, McLean M. Stress hyperglycemia: a prospective study examining the relationship between glucose, cortisol and diabetes in myocardial infarction. J Diabetes Complicat. 2019;33(4):329-34.

14. Prakash R, Parmley WW, Horvat M, Swan HJ. Serum cortisol, plasma free fatty acids, and urinary cathecholamines as indicators of complications in acute myocardial infarction. Circulation. 1972;45(4):736-45.

15. Lazzeri C, Valente S, D MG, Alfonso CM, Gensini GF. Determinants of Cpeptide levels and acute insulin resistance/sensitivity in nondiabetic STEMI role of Killip class. IJC Metab Endocrine. 2014;2:35-8.

16. Lonborg J, Vejlstrup N, Kelbaek H, Nepper-Christensen L, Jorgensen E. Impact of acute hyperglycemia on myocardial infarct size, area at risk, and salvage in patients with STEMI and the association with exenatide treatment: results from a randomized study. Diabetes. 2014;63(7):2474-85.

17. Pak S, Yatsynovich Y, Markovic J. A meta-analysis on the correlation between admission hyperglycemia and myocardial infarct size on CMRI. Hell J Cardiol. 2018;(59):174-78.

18. Tran HV, Gore JM, Darling CE, Ash AS, Kiefe Cl, Goldberg RJ. Hyperglycemia and risk of ventricular tachycardia among patients hospitalized with acute myocardial infarction. Cardiovasc Diabetol. 2018;17(1):10-1186.

19. Kataja A, Tarvasmäki T, Lassus J, Cardoso J, Mebazaa A, Køber L. The association of admission blood glucose level with the clinical picture and prognosis in cardiogenic shock - results from the CardShock study. Int J Cardiol. 2017;226:48-52.

20. Puig Domingo M. Platelet function and hyperglycemia in acute coronary syndrome. Rev Esp Cardiol (Engl Ed). 2014;67(1):3-5.

21. Undas A, Wiek I, Stepien E, Zmudka K, Tracz W. Hyperglycemia is associated with enhanced thrombin formation, platelet activation, and fibrin clot resistance to lysis in patients with acute coronary syndrome. Diabetes Care. 2008;31(8):1590-5.

22. Ege M, Guray U, Guray Y, Yilmaz MB, Demirkan B, Sasmaz A, et al. Relationship between TIMI frame count and admission glucose values in acute ST elevation myocardial infarction patients who underwent successful primary percutaneous intervention. Anadolu Kardiyol Derg/Anatol J Cardiol. 2011;11:213-7.

23. Kitano D, Takayama T, Nagashima K, Akabane M, Okubo K, Hiro T, et al. A comparative study of time-specific oxidative stress after acute myocardial infarction in patients with and without diabetes mellitus. BMC Cardiovasc Disord. 2016;102(16):1-6.

24. Kanaya AM, Dobrosielski DA, Ganz P, Creasman J, Gupta R, Nelacanti V, et al. Glycemic associations with endothelial function and biomarkers among 5 ethnic groups: the multi-ethnic study of atherosclerosis and the mediators 
of atherosclerosis in south Asians living in America studies. J Am Heart Assoc. 2013;2:e004283.

25. Moustafa TM. Utility of admission blood glucose level in prediction of short term course and extent of coronary artery occlusion in non-diabetic patients with ST segment elevation myocardial infarction. IJC Metab Endocrine. 2017;14:16-20.

26. Song $H$, Li H, Zhao S, Wang S, Li X. The predictive value of admission hyperglycemia in hospital and long-term mortality of diabetics versus nondiabetics with acute coronary syndrome. Zhonghua Nei Ke Za Zhi. 2013; 52(7):570-3.

27. Li DB, Hua Q, Guo J, Li HW, Chen H, Zhao SM. Admission glucose level and in-hospital outcomes in diabetic and non-diabetic patients with STelevation acute myocardial infarction. Intern Med. 2011;50(21):2471-5.

28. Liu Y, Yang YM, Zhu J, Tan HQ, Liang Y, Li JD. Haemoglobin A1C, acute hyperglycaemia and short-term prognosis in patients without diabetes following acute ST-segment elevation myocardial infarction. Diabet Med. 2012;29(12):1493-500.

29. Negreiros PH, Bau A, Nadruz W, Coelho FO, Matos-Souza JR, Coelho OR, et al. Intensive treatment of hyperglycemia in the acute phase of myocardial infarction: the tenuous balance between effectiveness and safety - a systematic review and meta-analysis of randomized clinical trials. Rev Assoc Med Bras. 2019;65(1):24-32.

30. Angeli F, Reboldi G, Poltronieri C, Lazzari L, Sordi M, Garofoli M, et al. Hyperglycemia in acute coronary syndromes: from mechanisms to prognostic implications. Ther Adv Cardiovasc Dis. 2015;9(6):412-24.

\section{Publisher's Note}

Springer Nature remains neutral with regard to jurisdictional claims in published maps and institutional affiliations.

- fast, convenient online submission

- thorough peer review by experienced researchers in your field

- rapid publication on acceptance

- support for research data, including large and complex data types

- gold Open Access which fosters wider collaboration and increased citations

- maximum visibility for your research: over $100 \mathrm{M}$ website views per year

At $\mathrm{BMC}$, research is always in progress.

Learn more biomedcentral.com/submissions 